\title{
Acción del factor de crecimiento epidérmico sobre el desarrollo de las células estriatales cultivadas
}

\author{
Lázara Castillo, Orlando Castellano, Johanka Soto, Juan C. Rosillo, Karelys de la Cuétara
}

\begin{abstract}
Resumen
En este trabajo se describe la acción del factor de crecimiento epidérmico (FCE) sobre las células del estriado embrionario en un sistema de cultivo disociado de neuronas y glías. El cultivo de células se preparó a partir de embriones de ratas de 16-17 días. En el sistema de cultivo empleado, la población celular fue cultivada durante 20-24 horas en un medio que contenía suero y, posteriormente, fue tratada con $20 \mathrm{ng} / \mathrm{mL}$ del FCE en un medio libre de suero. La eliminación del suero en este período inicial de desarrollo provocó una disminución apreciable de las células vivas en los cultivos tratados y en los controles. Al parecer, la población de células sobrevivientes estaba integrada, en su mayoría, por precursores celulares teniendo en cuenta su capacidad proliferativa. La acción del FCE sobre las células se manifestó en un aumento del número de células debido fundamentalmente a un estímulo de la proliferación de los precursores neuronales y astrocitos. Este efecto estuvo acompañado por una reducción de la diferenciación morfológica neuronal cuando se comparó con los cultivos controles. En los cultivos, a los 16 días, la detección de la actividad específica de la colina acetiltrasferasa evidenció la diferenciación de una subpoblación neuronal colinérgica, las cuales respondieron al tratamiento con el factor de crecimiento nervioso con un aumento de la actividad de la enzima.
\end{abstract}

\section{Summary}

This paper describes the effect of epidermal growth factor (EGF) on embryonic striatal cells in mixed neuronal-glial cultures prepared from 16-17 day old rat embryos. In the culture system employed, cell population was cultured for 20-24 hours in serum supplemented medium prior to being treated with $20 \mathrm{ng} / \mathrm{mL}$ epidermal growth factor (EGF) serum-free medium. This early withdrawal of serum from the culture medium caused an appreciable decline of viable cells in both control and treated cultures. It seems that the majority of surviving cells were precursors, taking into account their proliferative capacity. EGF action on cell population provoked an increase in cell numbers, mainly due to the stimulation of neuronal precursor and and astrocyte proliferation. This increase in cell proliferation was accompanied by neuronal morphological differentiation delay when compared to control cultures. Choline acetyltransferase specific activity detected in 16day old cultures, showed the differentiation of a cholinergic neuronal subpopulation, which responded to nerve growth factor treatment with enhanced enzyme activity.

Centro Internacional de Restauración Neurológica, Ciudad de La Habana, Cuba. 
El factor de crecimiento epidérmico (FCE) es un polipéptido con actividad mitogénica sobre diferentes tipos celulares (1). En el sistema nervioso central (SNC), su receptor se expresa en varias neuronas de la corteza cerebral, el cerebelo y el hipocampo $(2,3)$. Además, el FCE se ha detectado en varias regiones del SNC como la corteza cerebral, el hipocampo, el cerebelo y el estriado (4). Se considera que puede actuar sobre neuronas mitóticas y postmitóticas. De hecho, se demostró que actúa como un factor neurotrófico sobre neuronas cultivadas de la corteza cerebral, del telencéfalo subneocortical y del cerebelo, incrementando el crecimiento neuronal y la supervivencia (5-7). Su acción neurotrófica sobre las neuronas dopaminérgicas se describió como un incremento de la supervivencia y de la maduración $(8,9)$.

Se ha informado que la proliferación de los precursores celulares puede ser estimulada por los factores de crecimiento polipeptídico (10-12). En particular, el FCE estimula la proli-feración in vitro de los precursores neuronales aislados del cerebro embrionario y adulto de roedores (10, 13). Estas células fueron capaces de diferenciarse en neuronas, astrocitos y oligodendrocitos después de ser eliminado el FCE del medio de crecimiento. Informes recientes indican que al variar el microambiente celular es factible dirigir la diferenciación hacia la obtención de fenotipos neuronales específicos o de un determinado linaje celular (14-16).

Estos resultados han despertado un gran interés en el contexto de las investigaciones sobre las enfermedades degenerativas ya que podría ser un método potencialmente aplicable para aumentar el rendimiento de fenotipos específicos en las poblaciones celulares utilizadas en el trasplante neural.

El estudio de los factores neurotróficos ha demostrado que el espectro de la actividad de cualquiera de ellos sobre una población neuronal particular, está modulado por su estado de desarrollo y el microambiente que rodea las neuronas. En particular, el efecto mitogénico del FCE sobre los precursores celulares ha sido estudiado empleando sistemas donde éstos han estado aislados de otros tipos celulares. Sin embargo, determinar la acción del FCE en las condiciones de un cutivo con una población celular heterogénea podría representar un mayor acercamiento al comportamiento in vivo ya que, al menos, contempla algunas de las complejas interacciones que se producen en estos sistemas.

Las neuronas y las células gliales constituyen los principales tipos celulares del sistema nervioso, razón por la cual, para estudiar la acción del FCE, en este trabajo se utilizó un cultivo de células disociadas del estriado embrionario con una población celular inicial compuesta de neuronas y glías. Los resultados evidencian que, en las condiciones empleadas, el efecto fundamental fue el estímulo de la proliferación de los precursores neuronales y de los astrocitos. También, se demostró que el tratamiento con el factor no afectó la capacidad de la población colinérgica estriatal de responder a la acción del factor de crecimiento nervioso (FCN) con un aumento de la actividad de la colina acetiltransferasa.

\section{Materiales y métodos}

Los medios de cutivo empleados fueron Gibco, y los suplementos y otros reactivos de Sigma, a menos que se indique lo contrario.

\section{Cultivo de células estriatales}

El tejido estriatal se obtuvo de embriones de ratas Wistar de 16-17 días, disociado con tripsina al $0,1 \%$ a $37^{\circ} \mathrm{C}$ durante $20 \mathrm{~min}$, y la suspensión celular obtenida se filtró con una malla de nylon de $50 \mu \mathrm{m}$. Las células se centrifugaron y resuspendieron en el medio de placas (MP) compuesto por DMEN y HAM F-12 $(1: 1 \mathrm{v} / \mathrm{v})$, suero de ternera fetal $(10 \%)(\mathrm{STF})$, HEPES $15 \mathrm{mM}$, bicarbonato de sodio $1,2 \mathrm{~g} / \mathrm{L}$ y glutamina (2 mM). Esta suspensión celular fue inoculada en placas de 24 pozos tratados con poli-L-lisina $(0,1 \mathrm{mg} / \mathrm{mL})$ empleando una densidad celular de $2,5 \times 10^{5}$ células/placa. Los cultivos se incubaron a $37^{\circ} \mathrm{C}$ en atmósfera de $6 \%$ de $\mathrm{CO} 2$, saturada de humedad. 


\section{Tratamiento con FCE}

A las $22-24$ horas in vitro ( $\mathrm{t}=0$ ), los cultivos se lavaron con DMEM/HAM F-12 y se les añadió un medio libre de suero (MLS) que contenía la misma mezcla de nutrientes que el MP (excepto, el suero) y se suplementó con albúmina de suero bovino, fracción $\mathrm{V}(0,25 \%)$, putrescina $(60 \mathrm{mM})$, transferrina $(50 \mathrm{mg} / \mathrm{mL})$, insulina $(25 \mu \mathrm{g} / \mathrm{mL})(B D H)$, progesterona $(20$ $\mathrm{nM})$, selenito de sodio $(30 \mathrm{nM})$ y $20 \mathrm{ng} / \mathrm{mL}$ del FCE recombinante humano (FCE-rH) (producido por el Centro de Ingeniería Genética y Biotecnología, Cuba) a los cultivos tratados. En los controles no se añadió el factor.

Tratamiento I: adición de $20 \mathrm{ng} / \mathrm{mL}$ FCE-rH a intervalos de 48 horas (con el cambio de medio) (tres adiciones, FCE-3).

Tratamiento II: una adición de $20 \mathrm{ng} / \mathrm{mL}$ FCE-rH y un cambio de medio a MLS, sin el factor, a los cuatro días (FCE-1).

Para determinar el efecto del STF, se usó el MP al cual se añadió el FCE-rH siguiendo el tratamiento FCE-3.

Las células se cultivaron seis días en todos los tratamientos.

\section{Tratamiento con arabinosa citocina (ARAC)}

Para valorar la proporción de células de la población en estado proliferativo, se usó la ARAc, un inhibidor de la mitosis que es tóxico a las células en división. La ARAc $(5 \mu \mathrm{M})(\mathrm{BDH})$ se añadió a los cultivos tratados con FCE y a los controles a $t=2$ y se mantuvo de 24-48 h; después de eliminada, los cultivos se lavaron con DMEM/F-12, regresando a su condición original (controles o tratados).

\section{Determinación del crecimiento celular}

Las células estriatales cultivadas en diferentes condiciones experimentales, se tripsinizaron y resuspendieron en solución salina tamponada (PBS). El conteo de las células en la suspensión se realizó usando un hematocitómetro y azul de tripano $(0,4 \%)$ como colorante vital.

\section{Inmunocitoquímica}

Para la identificación de las neuronas, se usó un anticuerpo $(\mathrm{Ac})$ monoclonal que reconoce el neurofilamento (NF160 kD; Boehringer Mannheim, Alemania) y los astrocitos se identificaron con un Ac policlonal contra la proteína ácida fibrilar glial (GFAP; DAKO, Dinamarca). El estudio morfológico se realizó a los cultivos a $\mathrm{t}=0 \mathrm{y} \mathrm{t}=6$, los cuales se fijaron con parafomaldehído tamponado al $4 \%$, durante 20 min. La reacción inmunocitoquímica se llevó a cabo como sigue: las muestras, después de finalizado el período de fijación, se lavaron abundandemente con PBS; luego, fueron bloqueadas y permeabilizadas durante $20 \mathrm{~min}$ con una mezcla de STF al $20 \%$ y tritón X-100 al $0,25 \%$ en PBS. La incubación con el Ac primario se realizó durante toda la noche a $4^{\circ} \mathrm{C}$ Las diluciones de trabajo usadas fueron de 1:9 para el Ac contra NF $160 \mathrm{kD}$ y de 1:800 para el Ac contra GFAP. Después de lavadas tres veces, las muestras se incubaron durante $1 \mathrm{~h}$ con Ac anti-ratón (1:500) y anti-conejo (1:250) biotinilado (Boerhringer Mannheim, Alemania) de acuerdo con el primario utilizado, el Ac anti-NF 160 o el Ac anti GFAP, respectivamente. Posteriormente, las preparaciones se incubaron durante $1 \mathrm{~h}$ con el complejo EstreptAB conjugado con fosfatasa alcalina (GFAP; DAKO, Dinamarca). El revelado de la reacción se realizó usando naftol como sustrato y fast red como cromógeno. Finalmente, las preparaciones fueron contrastadas con hematoxilina y montadas usando Glicergel (DAKO, Dinamarca).

\section{Determinación de la actividad de la colina acetiltransferasa (CAT)}

A $t=6$, se cambió el medio a los cultivos que fueron tratados con FCE (FCE-3) y se les añadió MLS o MLS más $100 \mathrm{ng} / \mathrm{mL} F C N$ (aislado de las glándulas submaxilares de ratón en el Centro Internacional de Restauración Neurológica, Cuba) donde se mantuvieron 9 días, realizando cambios de medio cada 2-3 días, con adición de FCN a los cultivos mantenidos con la variante MLS más FCN. Al finalizar el período, se les determinó la actividad CAT.

Para la determinación de la actividad CAT, los cultivos se lavaron tres veces con un tampón

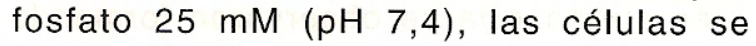


desprendieron usando policía y trituradas en un homogenizador de vidrio. La actividad CAT en el homogenizado se determinó mediante el método de Fonnum modificado (17), empleando como sustrato la $\left(1-{ }^{14} \mathrm{C}\right)$ acetil CoA $\left.50 \mu \mathrm{Ci} / \mathrm{mL}\right)$ y los resultados se expresaron como $\mathrm{nM} / \mathrm{h} / \mathrm{\mu g}$ de proteína.

\section{Análisis estadístico}

Todos los resultados fueron calculados como la media y el error estándar de la media (EEM) y la significancia estadística evaluada usando la prueba de la $U$ de Mann-Whitney.

\section{Resultados}

Antes de añadir el FCE, la población neuronal en el cultivo estaba representada por dos tipos morfológicos fundamentales: 1) células con un soma redondo, grande, refringentes bajo contraste de fase y sin procesos, cuya morfología coincide con la descrita para las células proliferativas $(18)$; 2) células con un soma alargado con uno o dos procesos cortos (figura 1a). Estos dos tipos celulares se identificaron como neuronas ya que se tiñeron con el anticuerpo anti-NF (figura 1b). En esta etapa del cultivo, se encontraron escasas células marcadas con el anticuerpo contra la GFAP con la morfología de los astrocitos en desarrollo (19).

La sustitución del MP por el MLS en los cultivos provocó una reducción en el número de células viables, tanto en los cultivos controles como en los tratados con el FCE, a un $55 \pm 8$ y $66 \pm 8 \%$, respectivamente, con respecto al número de células a $t=0$. En presencia del factor después de esta disminución inicial, se produjo un aumento progresivo de la densidad celular mientras que, en los controles, ésta se mantuvo aproximadamente constante (figura 2), evidenciando que el FCE estimuló la proliferación celular. La observación microscópica puso de manifiesto diferencias en la morfología de los cultivos tratados y de los controles. Después de la exposición al FCE, durante 6 días predominaron las células redondas y sin filamentos (figura 3a). Estas se tiñeron débilmente con el anticuerpo anti-NF en el soma $y$. en su mayoría se observaron formando

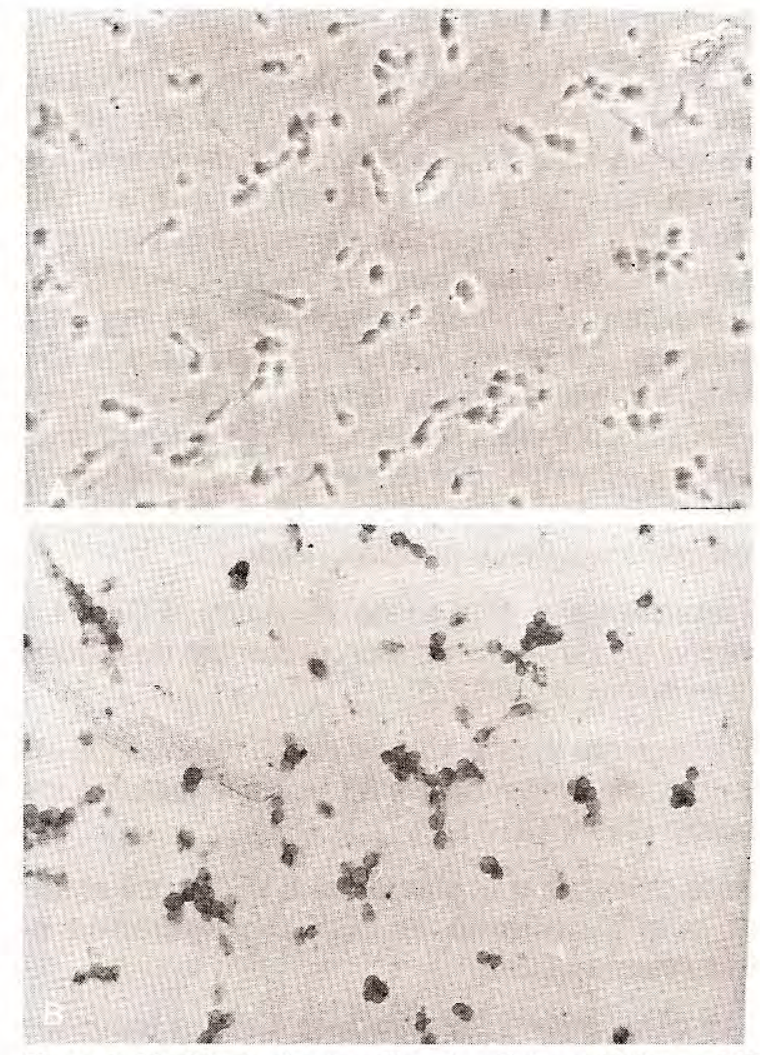

Figura1. Morfología de un cultivo de células estriales en MP a $\mathrm{t}=0$. A: cultivo fresco, contraste de fase. B: inmunotinción con el Ac anti-NF, campo brillante, $200 \mathrm{X}$.

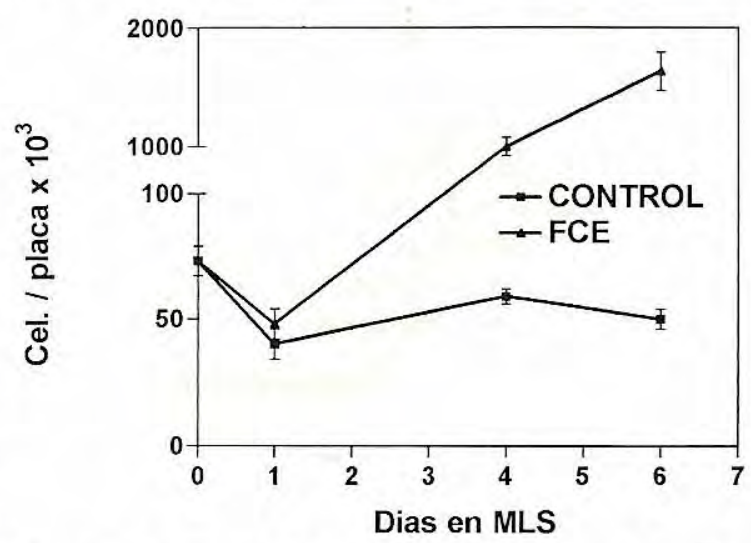

Figura 2. Efecto del FCE sobre el número de células. Los cultivos de células estriatales se prepararon siguiendo el procedimiento descrito en el texto. A $t=0$, las células se colocaron en placas en presencia o ausencia (controles) de $20 \mathrm{ng} / \mathrm{mL}$ de FCE-rH (FCE-3) y recolectadas mediante la tripsinización de éstas a diferentes tiempos. En presencia del FCE, el número de células aumentó progresivamente. Los valores representan la media \pm EEM de 5-6 cultivos en dos experimentos independientes; ${ }^{* *} p<0,01$. 

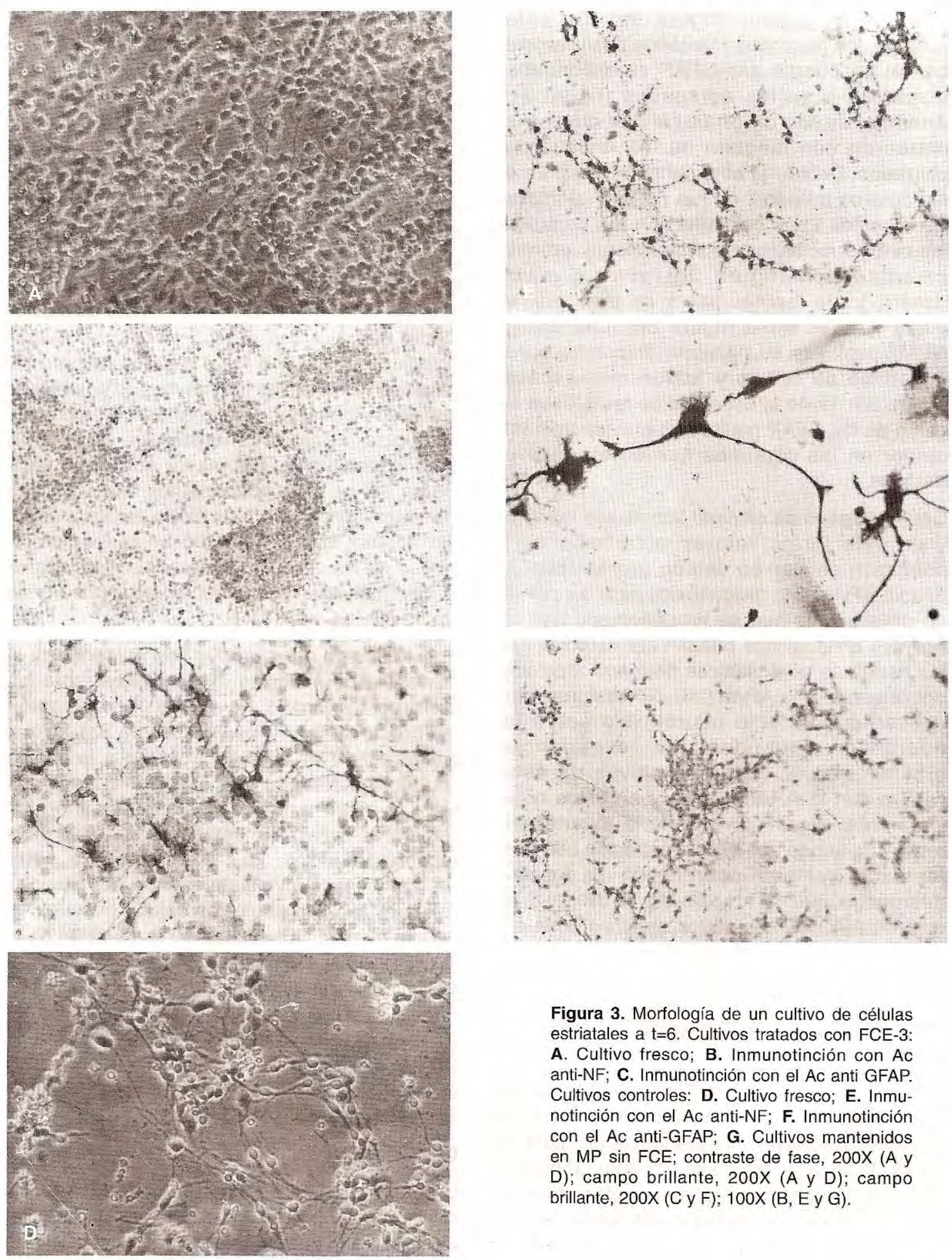

Figura 3. Morfología de un cultivo de células estriatales a $t=6$. Cultivos tratados con FCE-3: A. Cultivo fresco; B. Inmunotinción con AC anti-NF; C. Inmunotinción con el Ac anti GFAP. Cultivos controles: D. Cultivo fresco; E. Inmunotinción con el Ac anti-NF; F. Inmunotinción con el Ac anti-GFAP; G. Cultivos mantenidos en MP sin FCE; contraste de fase, 200X (A y D); campo brillante, 200X (A y D); campo brillante, 200X (C y F); 100X (B, E y G). 
grandes agregados (figura $3 b$ ). En estos cultivos, los astrocitos marcados positivamente con el anticuerpo anti-GFAP se encontraban dispersos o en los agregados (figura $3 \mathrm{c}$ ). Además, se vieron otras células que no se marcaron con ninguno de los anticuerpos utilizados. Debido al abundante crecimiento en los cultivos tratados, no fue posible cuantificar los distintos tipos celulares. En los controles, las células mostraron una morfología neuronal característica (figura $3 \mathrm{~d}$ ) con un mayor desarrollo de las neuritas y se marcaron en éstas y en el soma (figura $3 e$ ). Las células GFAP positivas se hallaban dispersas por la superficie de cultivo y fueron muy escasas (figura 3f). Tanto la densidad de las células NF como de las GFAP positivas fue evidentemente menor en los controles que en los cultivos tratados.

Con el objetivo de eliminar las células mitóticas y de esta forma valorar la fracción de la población celular en estado proliferativo, se añadió ARAc, una droga tóxica para las células en división. Aunque se ha observado que los agentes antimitóticos pueden ser neurotóxicos, las neuronas postmitóticas sólo son afectadas débilmente por la ARAc (20). No obstante, para descartar un efecto neurotóxico sobre las neuronas estriatales, en experiencias preliminares se trataron cultivos de estas células con la ARAc $(5 \mu \mathrm{M})$ y en éstos no se incrementó significativamente la muerte neuronal, sugiriendo que la concentración usada no fue excesivamente neurotóxica. La figura 4 demuestra que la adición de la droga a los controles y cultivos tratados, provocó la muerte de todas las células en las $24 \mathrm{~h}$ que siguieron al tratamiento, lo que sugiere que a $t=2$, tanto en los cultivos tratados como en los controles, la mayoría de las células estaban en estado mitótico.

El número de células en los cultivos a los seis días estuvo determinado por el tipo de tratamiento aplicado. La presencia continua del factor (FCE-3), en el medio, produjo un número significativamente mayor de células $(p<0,05)$ que cuando éste se adiciona solamente una vez al inicio del cultivo (figura 5). En ambos tratamientos, las diferencias con respecto al control fueron significativas $(p<0,01)$.

Informes recientes han mostrado que el crecimiento de los precursores inducido por el factor de crecimiento fibroblástico básico se afecta de forma diferente por el suero $(19,21)$. Para determinar la influencia del STF sobre la respuesta proliferativa de las células, el FCE se añadió al MP. En estas condiciones no aumentó significativamente el número de células (figura 6). Como referencia, en esta figura también se muestra el comportamiento observado cuando el medio utilizado fue el MLS. Como se puede apreciar, en el MP, a los 6 días, el número de células en los cultivos fue mayor que en el MLS. Aunque la densidad neuronal en el medio MP, evaluada cualitativamente en la tinción inmunocitoquímica, fue mayor que en el MLS (figura $3 \mathrm{e}, \mathrm{g}$ ), en ambos medios, las neuronas mostraron procesos neuríticos desarrollados. Así mismo, el MP permitió un mayor crecimiento de las células no neuronales, las cuales formaron una monocapa debajo de las neuronas (figura $3 \mathrm{~g}$ ), no así el MLS.

Resultados de otros grupos han evidenciado la existencia de múltiples interacciones entre los factores tróficos a través de la regulación recíproca de sus receptores $(22,23)$ lo que puede alterar la respuesta celular a la acción neurotrófica. Por otra parte, se ha informado que el FCN actúa sobre la población colinérgica estriatal en cultivo aumentando la actividad de la enzima CAT $(24,25)$. Atendiendo a esto, intentamos determinar la presencia de neuronas colinérgicas en la población celular después de tratada con el FCE, evaluando la actividad de la CAT y verificar si éstas eran capaces de responder al FCN. Los resultados de este análisis (figura 7) revelaron que la población celular producía niveles detectables de actividad de la CAT y que la adición del FCN a los cultivos aumentaba significativamente $(p<0,05)$ con respecto a los cultivos no tratados (MLS).

\section{Discusión}

La neurogénesis estriatal finaliza pocos días después del nacimiento. Por consiguiente, atendiendo al patrón de desarrollo estriatal (26, 
27), al tiempo en que se prepararon los cultivos (E16-17), problablemente más de la mitad de la población neuronal se encontraba en estado postmitótico, por lo que es posible inferir que, cuando se iniciaron los cultivos, la población de células NF-positivas estaba integrada por neuronas en diferentes estados de desarrollo. De esta forma, la diferente morfología de las células NF-positivas en los cultivos pudiera ser un reflejo del desarrollo neuronal.

Nuestras observaciones indican que el FCE estimuló la proliferación de las células estriatales en las condiciones de un cultivo donde, al menos, estaban presentes neuronas y astrocitos.

La acción del inhibidor mitótico ARAc para eliminar toda la población celular en los cultivos tratados con el FCE fue significativa y evidenció, aunque directamente, que la mayoría de las células presentes en el cultivo se encontraban en división. Se ha descrito un incremento en la proliferación de los astrocitos por el FCE (28), y en el sistema de cultivo usado también se observó este efecto, evaluado mediante la
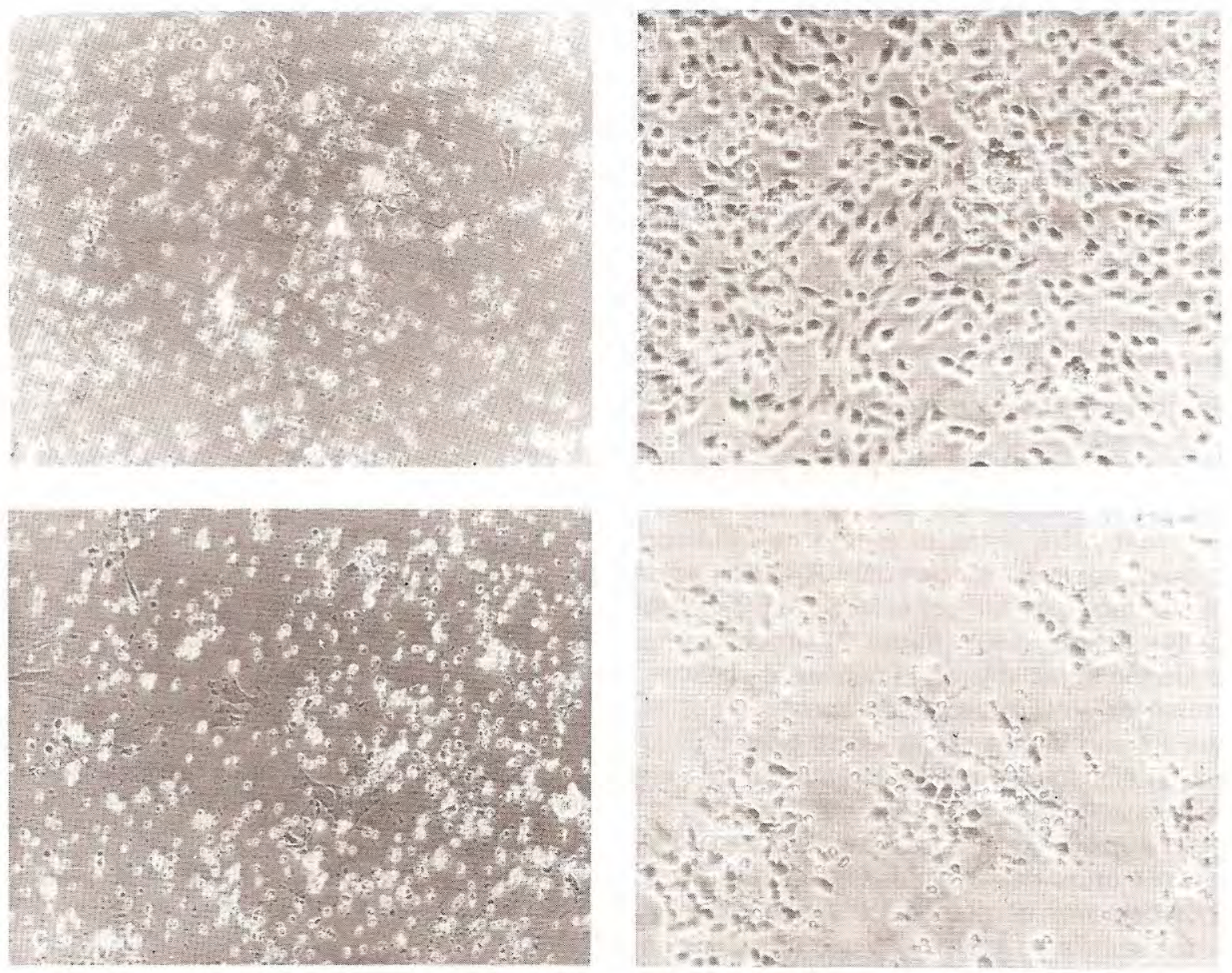

Figura 4. Microfotografía que ilustra el efecto de la ARAc sobre las células estriatales cultivadas en presencia (A y B) y ausencia del FCE (control) (C y D). La ARAc $(5 \mu \mathrm{M})$ se adicionó a los cultivos a $t=2$ (72 $\mathrm{h}$ in vitro) según se describe en el texto. Cultivo tratado (FCE-1) con (A) y $\sin (B)$ ARAc; control con (C) y $\sin$ (D) ARAc. La adición de la ARAc provocó la muerte de todas las células en las $24 \mathrm{~h}$ posteriores al tratamiento, tanto en los controles como en los cultivos tratados con el factor. Contraste de fase, 200X. 


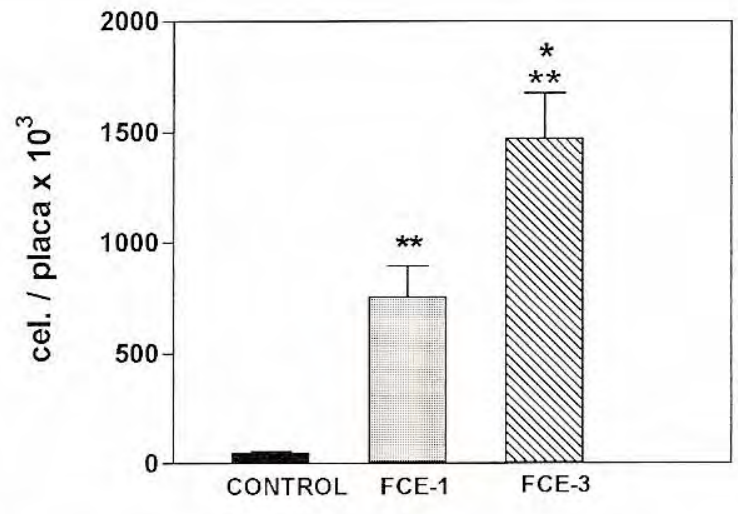

Figura 5. Efecto del tratamiento con FCE sobre la proliferación celular. En los cultivos donde el FCE se añadió tres veces, a intervalos de 48 h (FCE-3), el número de células a $t=6$ fue aproximadamente el doble, comparado con aquéllos donde se añadió una vez (FCE-1). Los valores representan la media \pm EEM de 5-6 cultivos en dos experimentos independientes; * $p<0,05$ (FCE-1 vs. FCE-3); ** $p<0,01$ (FCE-1 y FCE-3 vs. control).

inmunotincion para la GFAP (figura 3c, f). Así mismo, también fue evidente a partir de los resultados del marcaje inmunohistoquimico que hubo un aumento en la población neuronal bajo la acción del FCE.

Un conjunto de evidencias experimentales parece indicar que, en estas condiciones, se produjo un enriquecimiento de los precursores neuronales, al parecer debido a una mayor resistencia de éstos al efecto neurotóxico causado por la eliminación del suero del medio. La sustitución del MP por el MLS, 24 h después de las placas $(t=0)$ (figura 2) provocó una reducción apreciable en el número de células. Probablemente, aquellos fenotipos neuronales que habían alcanzado la etapa postmitótica fueron eliminados selectivamente, ya que en este estadio las células son más sensibles a las alteraciones del microambiente, que cuando están menos desarrolladas. Además, otros tipos celulares no neuronales tienen una baja supervivencia en los medios que no contienen suero (29), lo cual también se observó en los cultivos mantenidos en el MLS. Considerando que, en los cultivos controles, la ARAc eliminó también a todas las células, este comportamiento parece indicar que, en las condiciones

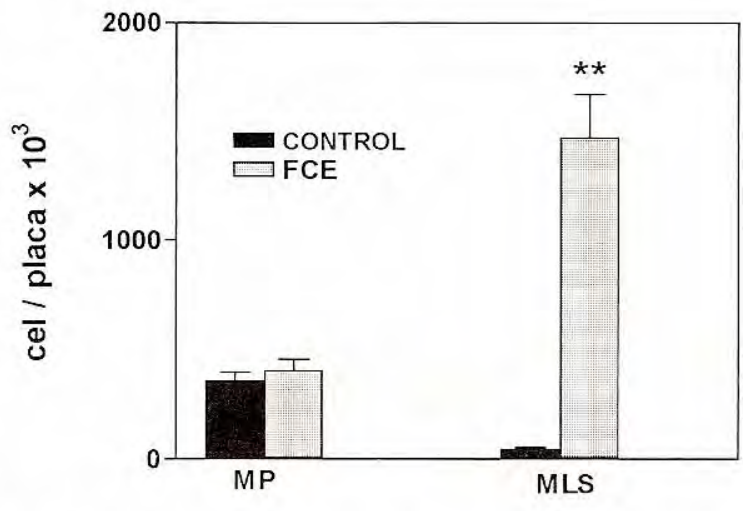

Figura 6. La presencia de STF en el medio eliminó el estímulo proliferativo del FCE. El número de células en los cultivos tratados no aumentó significativamente cuando el FCE-3 se añadió a un medio que contenía STF (MP). Para ser comparado, en la figura se muestra el incremento en el número de células obtenido cuando se empleó el MLS. Los valores se expresan como la media EEM de cuatro cultivos que representan uno de tres experimentos que mostraron el mismo comportamiento.

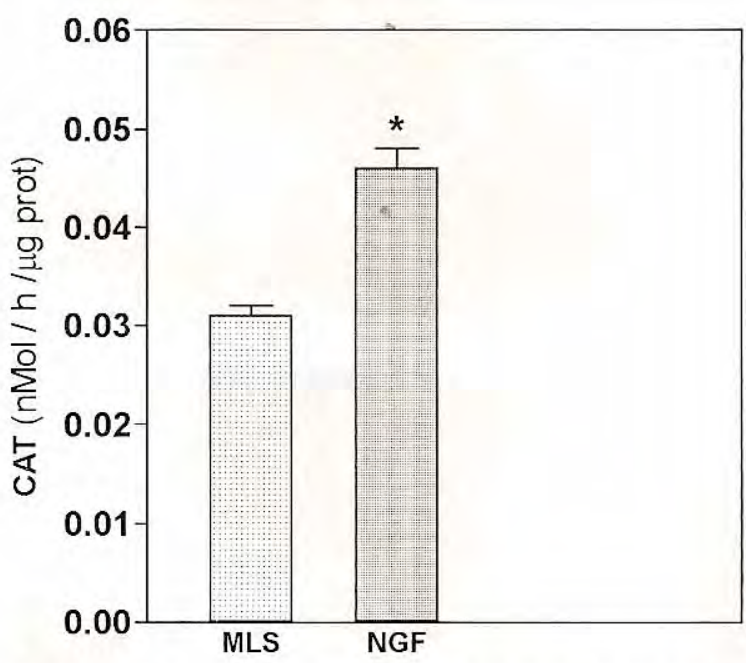

Figura 7. Actividad de la CAT en los cultivos de células estriales. $A \mathrm{t}=6$ en los cultivos tratados con FCE-3, el medio fue reemplazado por MLS o MLS + FCN, donde fueron cultivados como se describe en el texto. EI FCE produjo un incremento significativo de la actividad de la CAT. Los valores representan la media $\pm E E M, n=4$ en dos experimentos independientes.

empleadas, aun en ausencia del FCE, la mayoría de las células al menos estaban en la etapa inicial del ciclo de división celular. La neurotoxicidad causada por la eliminación del suero del medio donde crecen las células es un 
fenómeno observado en los cultivos primarios de neuronas postmitóticas de diferentes estructuras del sistema nervioso y en cultivos de la línea celular PC-12 (29-31). Informes recientes han mostrado que la eliminación del suero puede tener una toxididad selectiva sobre ciertos fenotipos neuronales (30). Por otra parte, un incremento de la proliferación de los precursores debido a la eliminación de determinadas poblaciones neuronales ha sido informado y se postula como uno de los mecanismos involucrados en el control de la neurogénesis durante el desarrollo del sistema nervioso (32). Por consiguiente, nuestros resultados y los de otros grupos aportan evidencias que sustentan que el FCE actuó sobre una población integrada mayoritariamente por precursores neuronales. Así mismo, nosotros interpretamos el efecto del FCE como un incremento de la supervivencia y la proliferación, atendiendo a que en ausencia del factor mueren un mayor número de células después del cambio de medio (figura 2) y a que después de los 6 días se produjo una disminución apreciable de las células en los controles. Sin embargo, como el aumento de la supervivencia y la proliferación suceden al mismo tiempo, no pudieron ser evaluados separadamente.

La adición del FCE a los cultivos, cada 48 h, incrementó aproximadamente dos veces el número de células con respecto a aquéllos que lo recibieron una sola vez y este comportamiento reflejó la necesidad de la presencia del factor para mantener la proliferación continua de las células, lo cual ha sido informado previamente (10).

En los cultivos tratados, la morfología de las células marcadas con el Ac anti-NF y las características del marcaje a los seis días fueron indicadores de una escasa diferenciación neuronal. La presencia de células que no se marcaron con ninguno de los anticuerpos pudiera estar relacionada con el mismo fenómeno aunque no se puede excluir la posible existencia de precursores de astrocitos y oligodendrocitos en la población celular que no fueron identificados inicialmente. La diferente morfología neuronal observada en los controles en MLS y en el MP (figura $3 \mathrm{e}, \mathrm{g}$ ) con respecto a los cultivos tratados (figura $3 b$ ), argumenta a favor de que la limitada diferenciación neuronal en los cultivos en MLS tratados con el FCE fue una consecuencia del incremento de la proliferación de las células. Esta interpretación coincide con los informes realizados en otros sistemas sobre la existencia de una relación inversa entre la proliferación y la diferenciación (33-35).

En presencia del STF, el FCE no incrementó el número de células. Dada la natulareza compleja e indefinida del suero, no quedó determinada la causa del antagonismo del suero sobre el efecto proliferativo del FCE, lo cual tampoco fue objeto de este estudio. Se debe anotar que, aunque en el MLS las neuronas sólo sobrevivieron por un período corto de tiempo, este medio permitió la diferenciación morfológica. Estos resultados indican la conveniencia de optimizar la composición del medio para lograr una mayor supervivencia neuronal; no obstante, en las condiciones empleadas, éste resultó útil para para detectar el efecto del FCE.

La expresión de la actividad de la CAT por la población celular tratada con el FCE después de ser mantenida 9 días en ausencia del factor, indicó que una subpoblación de células diferenció hacia el fenotipo colinérgico. Estas células respondieron a la acción del FCN aumentando la actividad específica de la CAT, una característica mostrada por la población de interneuronas colinérgicas estriatales. La respuesta al FCN pudo estar relacionada con un incremento de la supervivencia a la mitosis de las neuronas sensibles, alternativas que deben ser dilucidadas experimentalmente. No se pudo valorar si el tratamiento con el FCE influyó sobre la expresión de la CAT por las células ya que no se evaluó la actividad de la enzima en los cultivos controles (MLS sin FCE), debido a la no supervivencia neuronal en éstos al tiempo en que se determinó la enzima.

A diferencia del comportamiento observado en la población celular estudiada, en estudios previos, el fenotipo colinérgico no se obtuvo como resultado de la diferenciación de los precursores aislados del estriado adulto y embrionario en 
diferentes condiciones de cultivo. Estos trabajos difieren del aquí informado tanto en los procedimientos experimentales empleados como en el estado de desarrollo de los precursores que fueron diferenciados $(10,13)$.

En las condiciones de este estudio, el FCE influyó sobre la población de células estriatales estimulando la proliferación de los precursores neuronales y de los astrocitos. Por consiguiente, el patrón de desarrollo neuronal in vitro cambió hacia un retardo en los procesos de diferenciación morfológica neuronal. La detección de la actividad CAT en la población celular evidenció la presencia de una subpoblación neuronal colinérgica capaz de responder a la acción del FCN. Aunque una simplificación de la composición celular al parecer tuvo lugar en los cultivos, estos resultados muestran que la proliferación de los precursores estriatales se puede estimular por el FCE bajo condiciones experimentales diversas como la aquí informada y las empleadas por otros autores $(10,13,15,18)$.

Si las condiciones del cultivo condicionan cuáles poblaciones específicas de precursores celulares serán las estimuladas, es un aspecto que debe ser investigado.

Experimentos para determinar el potencial de diferenciación de los precursores celulares, así como la composición fenotípica neuronal en los cultivos, son necesarios para establecer la influencia del sistema de cultivo empleado en la obtención de fenotipos neuronales especí-ficos.

\section{Agradecimientos}

Al Centro de Ingeniería Genética y Biotecnología por el suministro del FCE-rH utilizado en nuestras experiencias.

\section{Referencias}

1. Carpenter G, Cohen S. Epidermal growth factor. Ann Rev Biochem 1979;48:193-213.

2. Adamson ED, Meek J. The ontogeny of epidermal growth factor receptors during mouse development. Dev Biol 1984;103:62-70.

3. Gómez-Pinilla F, Knaver DJ, Nieto-Sampedro M. Epidermal growth factor receptor immunoreactivity in the rat brain. Development and cellular localization. Brain Res 1988;438:385-90.
4. Lazar LM, Blum M. Regional distribution and developmental expression of epidermal growth factor and transforming growth factor- mRNA in mouse brain by a quantitative nuclease protection assay. $\mathrm{J}$ Neurosc 1992;12:1688-97.

5. Morrison RS, Kornblum HI, Leslie FM, Bradshaw RA. Trophic stimulation of cultured neurons from neonatal rat brain by epidermal growth factor. Science 1987;238:72-5.

6. Morrison RS, Keating RF, Moskal JR. Basic fibroblast growth factor and epidermal growth exert differential trophic on CNS neurons. J Neurosc 1988;21:719.

7. Kornblum HI, Raimon HK, Morrison RS. Epidermal growth factor and basic fibroblast growth factor: effect on overlapping populations of neocortical neurons in vitro. Brain Res 1990;535:255-63.

8. Casper D, Mytilineou C, Blum M. EGF enhances the survival of dopamine neurons in rat embryonic mesencephalon primary culture. J Neurosc Res 1991;30:372-81.

9. Hadjiconstantinou M, Fitkin G, Dalia A, Neff NH. Epidermal growth factor enhances striatal dopaminergic parameters in the 1-methyl-4-phenyl-1,2,3,6tetrahydro-pyridine treated mouse. J Neurosc 1991;57:479-82.

10. Reynolds BA, Weiss S. Generation of neurons and astrocytes from isolated cell of the adult mammalian central nervous system. Science 1992;5052:1707-10.

11. Mytilineou C, Park TH, Shen J. Epidermal growth factor induced survival and proliferation of neuronal precursor cells from embryonic rat mesencephalon. Neurosci Lett 1992;135:62-66.

12. Gensberger C, Labourdette G, Sensenbrenner $M$. Brain basic fibroblast growth factor stimulates the proliferation of neuronal precursor cells in vitro. FEBS Lett 1987;217:1-5.

13. Reynold BA, Tetzalaff H, Weiss S. A multipotent EGF-responsive striatal embryonic progenitor cell produces neurons and astrocytes. J Neurosci 1992; 4565-74.

14. Bartlett PF, Richards LR, Kilpatrick TJ, Talman PS, Bailey KA, Brooker GJF, et al. Regulation of neural precursor differentiation in the embryonic and adult forebrain. Clin Exp Pharmacol Physiol 1995;22:559-62.

15. Daasi M, Reynolds BA, Weiss S. EGF-responsive stem cell progeny generates new neuronal phenotypes when cocultured with striatal astrocytes. Abtracts from The Fifth Int Symp on Neural Transplantation, Paris, 1994:54.

16. Ferr RT, Levitt P. Regulation of regional differences in the differentiation of cerebral cortical neurons by EGF family-matrix interactions. Development 1995; 121:1151-60. 
17. Fonum F. A rapid radiochemical method for the determination of coline acetyltransferase. $\mathrm{J}$ Neurochem 1975;24:407-9.

18. Vescovi AL, Reynolds BA, Fraser DD, Weiss S. bFGF regulates the proliferative fate of unipotent (neuronal) and bipotent (neuronal/glial) EGF-generated CNS progenitor cells. Neuron 1993;11:951-66.

19. Fedoroff S, Houle J, Kalvins VI. Intermediate filaments and neural cells differentation. Int $\mathrm{J}$ Neurol 1983;17:30-45.

20. Hertz L, Juulink BHJ, Szuchet S. Handbook of neurochemistry. In: Lajtha A, ed. Cell cultures. Plenum Publishing Corporation, 1985:603-61.

21. Kirpatrick TJ, Bartlett PF. Cloning and growth of multipotential neural precursors: requirements for proliferation and differentiation. Neuron 1993;10:255-65.

22. Birren SJ, Anderson DJ. A V-myc-immortalized sympathoadrenal progenitor cell line in which neuronal differentiation is initiated by FGF but not NGF. Neuron 1990;4:189-201.

23. Cattaneo E, Mackay R. Proliferation and defferentiation of neuronal stem cells regulated by nerve growth factor. Nature 1990;347:762-65.

24. Hatanaka $\mathbf{H}$, Tsukui $\mathbf{H}$. Differential effects of nerve growth factor and glioma conditioned medium on neurons cultured from various regions of fetal rat central nervous system. Dev Brain Res 1986;30:47-56.

25. Martínez JH, Dreyfrus CF, Jonakait M, Black LB. Nerve growth factor promotes cholinergic development in brain striatal cultures. Proc Natl Acad Sci USA 1985;82:7777.
26. Bayer SA. Neurogenesis in the rat neostriatum. Int Dev Neurosci 1984;2:163-75.

27. Marchand R, Lajoie L. Histogenesis of the striopallidal system in the rat. Neurogenesis of its neurons. Neuroscience 1986;17:573-90.

28. Simpson DL, Morrison RS, de Vellis J, Herschman HR. Epidermal growth factor binding and mitogenic activity on purified populations of cells from the central nervous system. J Neurosci 1982;8:453462.

29. Bottenstein JE, Skaper SD, Varon SS, Sato GH. Selective survival of neurons from chick embryo sensory ganglionic dissociates utilizing serum-free supplemented medium. Exp Cell Res 1980;125:183-90.

30. Takeshima T, Lohnston JM, Commissiong JW. Mesencephalic type 1 astrocytes rescue dopaminergic neurons from death induced by serum deprivation medium. J Neurosci 1994;14:4769-79.

31. Kobayashi Y, Saheki T, Shinozawa T. Induction of PC12 cell death, apoptosis, by a sialoglycopeptide from bovine brain. Biochem Bioph Res Comm 1994;203:1554-9.

32. Rohrer H. The role of growth factors in the control of neurogenesis. Eur J Neurosci 1990;2:1005-15.

33. Filipak M, Estervig DN, Tzen C-Y, Minoo P, Hoerl BJ, Maercklein et al. Integrated control of proliferation and differentiation of mesenchymal stem cells from mammalian CNS. Neuron 1988;80:439-48.

35. Lillien LE, Raff MS. Differentiation signals in the CNS: type-2 astrocyte development in vitro as a model system. Neuron 1990;5:11-119. 